\title{
Genome-wide sequence and functional analysis of early replicating DNA in normal human fibroblasts Stephanie M Cohen* ${ }^{* 1}$, Terrence S Furey ${ }^{\dagger 2}$, Norman A Doggett ${ }^{3}$ and David G Kaufman ${ }^{1}$
}

\author{
Address: ${ }^{1}$ Department of Pathology and Laboratory Medicine, University of North Carolina, Chapel Hill, North Carolina 27599, USA, ${ }^{2}$ Institute \\ for Genome Sciences and Policy, Duke University, Durham, NC, 27708, USA and 3Bioscience Division, Los Alamos National Laboratory, Los \\ Alamos, New Mexico 87545, USA \\ Email: Stephanie M Cohen* - stepmi@med.unc.edu; Terrence S Furey - tsfurey@duke.edu; Norman A Doggett - doggett@lanl.gov; \\ David G Kaufman - uncdgk@med.unc.edu \\ * Corresponding author †Equal contributors
}

Published: 29 November 2006

BMC Genomics 2006, 7:301 doi:10.1/86/147|-2164-7-301
Received: II October 2006

Accepted: 29 November 2006

This article is available from: http://www.biomedcentral.com/I47I-2164/7/30I

(c) 2006 Cohen et al; licensee BioMed Central Ltd.

This is an Open Access article distributed under the terms of the Creative Commons Attribution License (http://creativecommons.org/licenses/by/2.0), which permits unrestricted use, distribution, and reproduction in any medium, provided the original work is properly cited.

\begin{abstract}
Background: The replication of mammalian genomic DNA during the $\mathrm{S}$ phase is a highly coordinated process that occurs in a programmed manner. Recent studies have begun to elucidate the pattern of replication timing on a genomic scale. Using a combination of experimental and computational techniques, we identified a genome-wide set of the earliest replicating sequences. This was accomplished by first creating a cosmid library containing DNA enriched in sequences that replicate early in the $S$ phase of normal human fibroblasts. Clone ends were then sequenced and aligned to the human genome.

Results: By clustering adjacent or overlapping early replicating clones, we identified 1759 "islands" averaging $100 \mathrm{~kb}$ in length, allowing us to perform the most detailed analysis to date of DNA characteristics and genes contained within early replicating DNA. Islands are enriched in open chromatin, transcription related elements, and Alu repetitive elements, with an underrepresentation of LINE elements. In addition, we found a paucity of LTR retroposons, DNA transposon sequences, and an enrichment in all classes of tandem repeats, except for dinucleotides.

Conclusion: An analysis of genes associated with islands revealed that nearly half of all genes in the WNT family, and a number of genes in the base excision repair pathway, including four of ten DNA glycosylases, were associated with island sequences. Also, we found an overrepresentation of members of apoptosis-associated genes in very early replicating sequences from both fibroblast and lymphoblastoid cells. These data suggest that there is a temporal pattern of replication for some functionally related genes.
\end{abstract}




\section{Background}

A highly organized and strictly controlled process is necessary to accurately replicate the six billion base pairs of DNA that are tightly packaged within the confined volume of the human diploid nucleus. In order to accomplish this task, DNA replication is initiated at distinct sites in the genome as cells enter the $S$ phase [1]. The regulation of initiation is important because once the $S$ phase begins, a cascade of events results in the successive activation of new replication clusters in a temporally and spatially ordered manner $[2,3]$. The order of activation of the estimated 30,000 replicons in the human genome [4] is maintained through successive cell cycles [5] and is tissue specific $[5,6]$. It is not yet fully understood how this sequential firing of replicons, resulting in the orderly progression through $\mathrm{S}$ phase, is regulated in human cells, but disruption of this process can have far reaching consequences that include acquisition of genetic instability leading to cancer.

The distribution of early and late replicating DNA is seen cytogenetically when metaphase chromosomes are Giemsa banded. It has been known for some time that Giemsa-negative or reverse (R) bands replicate early in $S$ phase while Giemsa-positive (G) bands replicate late [79]. While the exact molecular basis for chromosomal banding is not understood, it has been proposed to be related to differences in chromatin condensation [10], the arrangement of scaffold-loop structures [11] or differences in GC content between neighboring regions [12]. Indeed, R bands were reported to have a higher GC content [9] and have a higher density of genes $[13,14]$ and CpG islands [15] than G bands. Short and long interspersed nuclear elements (SINE and LINE, respectively) were also found to be unevenly distributed; a higher SINE frequency was found in $\mathrm{R}$ bands while LINE elements were disproportionately found in G bands $[16,17]$.

The distribution of the above-mentioned sequence features of early replicating DNA in the giemsa-negative bands (R-bands) were determined using cytogenetic methods. More recently, studies by Woodfine et al. $[18,19]$ confirmed the cytogenetic data, utilizing a microarray approach. Microarrays containing human genomic sequences were used for comparative hybridization of DNA isolated from $S$ phase and $G_{1}$ cells. Using this methodology, they found a positive correlation between early replication and CpG islands, GC content, expressed genes, and Alu repeats (a member of the SINE class of repeats). A negative correlation was found with LINE elements [19]. White et al. [20] who found enrichment of transcriptionally active (but non-protein encoding) regions in early replicating sequences from chromosome 22 used a similar approach. Jeon et al. [21] investigated replication timing on chromosome 21 and 22 using high density genome-til- ing arrays. Gene density, exon density, and gene expression were all highly correlated with early replication in their study. They hypothesized that an open chromatin environment, as reflected by high exon density separates early replicating DNA from that replicating later. In another study, Gilbert et al. [22] separated compact and open chromatin fibers and studied their genomic distribution using microarrays containing a sub-set of genomic sequences. They found a positive correlation between open chromatin and early replication according to results from low-density genome-wide arrays. This correlation disappears however, when comparing chromatin structure data and time of replication from high-density arrays for chromosome 22.

We have taken a different approach to study characteristics of DNA that replicates early in the $S$ phase. We reported previously the construction of a cosmid library enriched in early replicating sequences from normal human fibroblasts [23]. In the present study, we endsequenced and mapped clones from this library, identifying "islands" where clones were adjacent or overlapping. We then verified that our island sequences exhibited the features of early replicating DNA reported by others (i.e., high GC, Alu, and gene content, and open chromatin structure) as well as active promoters. Also, we determined more precisely the time of replication for selected islands and compared them to data reported by Woodfine et al. $[18,19]$. We performed a more extensive analysis of repetitive sequences in early replicating DNA, including long terminal repeats (LTRs), DNA transposons, and inverted, tandem, and simple repeats. We also identified genes associated with islands of early replicating sequences and found an enrichment in WNT genes and DNA glycosylases and, using the GOstat program, an overrepresentation of genes involved in apoptosis. Finally, we analyzed genes that overlapped markers tested by Woodfine et al. $[18,19]$ for replication timing and found that apoptotic genes also replicate very early in lymphoblastoid cells.

\section{Results and discussion Synchronization of normal human fibroblasts and library construction}

The construction of a subgenomic cosmid library enriched in early replicating sequences has been previously described [23]. Briefly, normal human fibroblasts (NHF1) obtained in this laboratory from neonatal foreskin [24] were synchronized to early in the $S$ phase by a combination of confluence arrest, followed by replating at lower cell density in the presence of aphidicolin. The DNA polymerase inhibitor aphidicolin allows for the initiation of DNA replication, but dramatically slows replication fork progression $[25,26]$ without altering the order of gene replication [27]. Bromodeoxyuridine (BrdUrd) was 
added to aphidicolin-containing medium to label DNA replicated as cells entered the S phase. Nuclear DNA purified from cells harvested $24 \mathrm{~h}$ after replating was partially digested with Sau 3AI, and hybrid-density DNA was separated in $\mathrm{CsCl}$ gradients. The purified early-replicating DNA was cloned into the sCos1 cosmid vector. Clones were transferred individually into the wells of 96 microtiter plates $(9,216$ potential clones).

Figure 1 shows a typical flow cytometry analysis of NHF1 cells after 24 hrs in aphidicolin and BrdUrd. This profile shows that with this method of synchronization, most cells are in G0/G1 and at the G1/S border. If we look exclusively at the cells containing BrdUrd in the experiment shown in Figure 1, 80.4\% were in early S, 13.3\% were in middle S, and $6.3 \%$ were in late S. Since only BrdUrd-labeled DNA was used to generate the cosmid library, these flow cytometry values give us an approximate $S$ phase distribution of DNA in our islands. This figure illustrates that most of the DNA used to create the cosmid library was isolated from cells that were in early $S$ phase. It also shows that although the cells were well synchronized a small but measurable fraction of cells were in middle and late $S$. The presence of these middle and late $S$ phase cells in the synchronized population are probably the result of the approximately $3 \%$ of cells that are still cycling in the confluence arrested cultures. We have found that this number can be reduced by increasing the amount of times held at confluence arrest. Increased time at confluence arrest however, will result in less cells cycling after they are replated at lower density (unpublished observations).

\section{Identification of islands}

End sequencing of 9216 cosmid clones from a library enriched in early replicating DNA yielded high quality sequences for both ends of 6370 clones; reliable sequence for a single end was obtained for another 1521 clones, for a total of 7891 clones with at least one end sequenced. The remaining 1140 clones produced only poor quality traces or showed evidence of contamination. Successful reads were aligned to the genome as detailed in the Methods section, resulting in the placement of 7614 (96.5\%) clones, 5818 using both ends. Due to segmental duplications and repetitive sequences at their ends, some clones could not be placed uniquely and were discarded, leaving $7455(94.5 \%)$ clones for further analysis. We theorized that clusters of clones or "islands" are the result of redundant sampling of early replicating regions and provide an effective mechanism for screening out most non-early replicating clones that may be the result of a small amount of total genomic DNA contaminating the BrdUrd-labeled DNA recovered from density gradients. We looked for evidence of clustering of early replicating cosmid clones by defining early replicating islands as regions in the genome

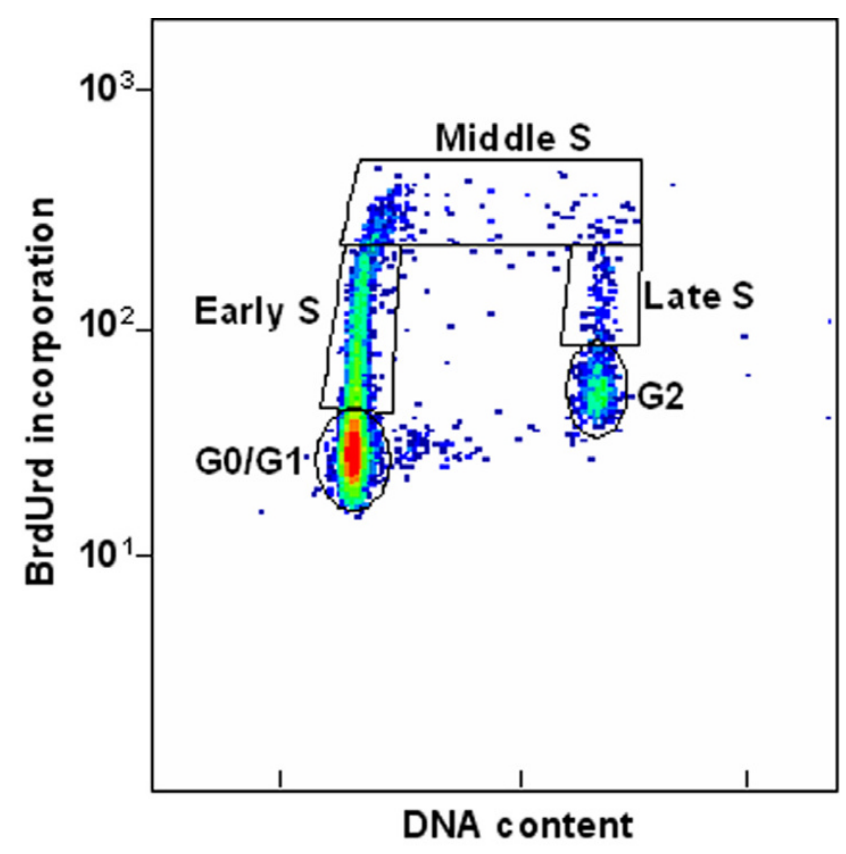

\section{Figure I}

Flow cytometry of synchronized NHFI cells. Cells were grown to confluence arrest and replated at low density in the presence of aphidicolin and BrdUrd as described. After $24 \mathrm{hrs}$ cells were collected and analyzed by flow cytometry. The ordinate of this graph shows BrdUrd incorporation as indicated by fluorescently-labeled anti-BrdUrd antibody and the abscissa shows DNA content as indicated by propidium iodide staining. The boxes outline areas that were analyzed for cell number.

$\leq 175 \mathrm{~kb}$ in length, where two or more clones were localized, with a maximum distance of $100 \mathrm{~kb}$ between clones. We found 1759 islands that met these criteria; they had an average island size of $\sim 100 \mathrm{~kb}$, and included 4250 clones. We noticed that the average size of these islands is in close agreement with the average size of a replicon [4], and it is likely that sequences within each island replicate at the same time. An example of one island, as displayed in a mirror copy of the UCSC browser [28] available at Duke University [29], is shown in Figure 2. Islands were found on every chromosome, but were not equally distributed. Table 1 shows the relative enrichment or under-representation of island DNA based on the genomic percentage of each chromosome. Chromosome 19, which comprises $2.25 \%$ of the genome, was the most enriched, with $4.4 \%$ of the island DNA originating from this chromosome. In contrast, sequences from the $\mathrm{X}$ and $\mathrm{Y}$ chromosomes had the lowest representation in island DNA. This distribution of islands corresponds well with the mean replication timing ratios determined for each chromosome reported by Woodfine et al. [19] for lymphoblastoid cells. As shown in Table 1, the five chromosomes with the highest per- 


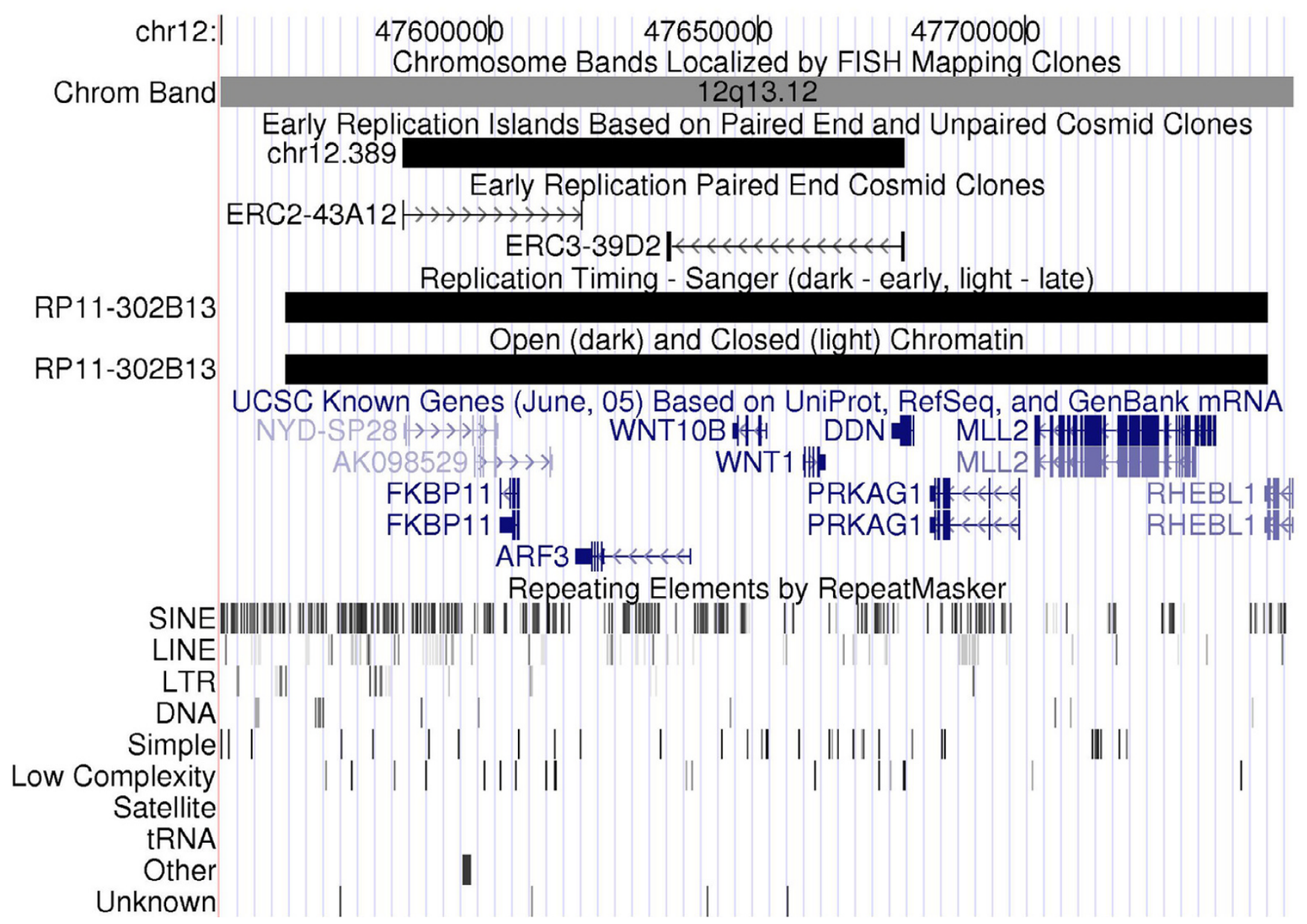

Figure 2

Island represented in mirror of UCSC Genome Browser. The early replication island chr/2.389 is displayed as an annotation track in a mirror copy of the UCSC Genome Browser and is available at [29]. The cosmid clones that support this island, ERC2-43AI 2 and ERC3-39D2, are also shown below. This island overlaps a BAC clone, RPII-302BI3, for which both replication timing $[18,19]$ and an open chromatin status [22] are available. The dark boxes indicate that this region was found to replicate early (timing ratio $=2.00$ ) and to have an open chromatin conformation ( $\log 2$ open $=2.73$ ). The 200-kb region displayed is gene dense, including two WNT genes, is highly enriched in SINE repeat elements, and shows a paucity of LINE, LTR, and DNA transposons.

centage of island DNA corresponds to five of the six chromosomes with the earliest replicating timing as determined by Woodfine et al. [19].

It has been previously shown in mammalian cells that chromosomal bands that do not stain with Giemsa tend to replicate early while bands that do stain replicate late [7-9]. Using the estimated chromosomal band positions available in the UCSC Genome Browser [30], the percentage of early replicating island DNA in each band class was determined. There is a significant enrichment $(\mathrm{p}<0.001$, $\chi^{2}$ test) in G-negative bands with $~ 59 \%$ of island DNA in this band class as compared to $45 \%$ of total sequenced genomic DNA in these bands. In contrast, only $17 \%$ of islands were found in the two darkest staining and hetero- chromatic late-replicating bands, while nearly 33\% of genomic DNA is contained within these bands. When we examined those markers used by Woodfine et al. [18,19] that comprise the earliest replicating $25 \%$ of markers tested (markers with replication timing ratios > 1.75), we found that $\sim 70 \%$ were located in G-negative bands. From these studies with higher resolving power than previous cytogenetic analyses, we concluded that while early replicating sequences are found predominantly in G-negative bands, a sizeable portion is not.

\section{Further validation of replication timing using synchronized normal human fibroblasts}

Replication timing data in the Woodfine et al. studies $[18,19]$ mentioned above was determined in lymphoblas- 
Table I: Distribution of islands.

\begin{tabular}{ccc}
\hline Chromosome & Percent Enrichment & $\begin{array}{c}\text { Mean Replication Timing } \\
\text { Ratio }^{2}\end{array}$ \\
\hline 19 & $198 \%$ & 1.72 \\
17 & $183 \%$ & 1.64 \\
16 & $175 \%$ & 1.56 \\
22 & $160 \%$ & 1.75 \\
15 & $123 \%$ & 1.57 \\
10 & $120 \%$ & 1.49 \\
11 & $113 \%$ & 1.49 \\
1 & $112 \%$ & 1.52 \\
7 & $110 \%$ & 1.45 \\
20 & $101 \%$ & 1.60 \\
12 & $97 \%$ & 1.50 \\
9 & $96 \%$ & 1.44 \\
8 & $89 \%$ & 1.39 \\
6 & $82 \%$ & 1.44 \\
14 & $82 \%$ & 1.46 \\
18 & $79 \%$ & 1.42 \\
2 & $79 \%$ & 1.43 \\
5 & $73 \%$ & 1.42 \\
3 & $71 \%$ & 1.43 \\
21 & $66 \%$ & 1.42 \\
4 & $55 \%$ & 1.34 \\
13 & $48 \%$ & 1.36 \\
$X$ & $28 \%$ & 1.38 \\
$Y$ & $25 \%$ & 1.32 \\
& &
\end{tabular}

I- The percentage of total DNA in islands that originated from each chromosome was determined and compared to the percentage of genomic DNA for each chromosome.

2- Mean replication timing ratio for each chromosome as reported in Woodfine et al. [19]. Higher numbers indicate an earlier average time of replication.

toid cells while our library was derived from normal human fibroblasts. In the Woodfine et al. studies, genomic DNA from $S$ phase lymphoblastoid cells was hybridized to microarrays containing clones that were distributed at $\sim 1 \mathrm{Mb}$ intervals across the genome, at a resolution of $\sim 70 \mathrm{~kb}$ on chromosome 22 [19], and $\sim 94 \mathrm{~kb}$ on chromosome 6 [18]. The hybridization signal from $S$ phase cells was compared to the hybridization signal for DNA isolated from $G_{1}$ cells to determine the replication timing ratio. This ratio reflects the copy number of each clone in the S phase DNA, and ranged from $~ 1.0$ to 2.0, with 2.0 representing the earliest replicating sequences tested. We decided to test several islands using a quantitative PCR assay $[31,32]$ to check for concordance between their replication time in fibroblasts and the replication timing ratio determined by the Woodfine group in lymphoblastoid cells $[18,19]$. A total of 20 markers from 10 islands were tested (Table 2). To provide a robust comparison, islands containing three or more clones were chosen to cover a variety of replication timing ratios as determined by Woodfine et al. $[18,19]$ with the high-resolution data for chromosomes 6 and 22. For each primer set (Table 2), an equal amount of replicating DNA from samples representing seven 1-h windows of the S phase was tested and the approximate time of replication was determined as described in the Methods section.

Figure 3 illustrates the primary data for three markers; the results for all markers tested are listed in Table 2 and are the average of PCR analyses from two separate synchronizations. We were able to assign replication times for 17 of the 20 markers, with good agreement between the two synchronizations. Only one marker, chr22.1102A, gave results that did not allow for replication time assignment. In the samples from both synchronization experiments, this chromosome 22 marker was enriched in DNA replicated during the $1^{\text {st }}$ and the $5^{\text {th }}$ hr of the synchronous $S$ phase. At another island, (primer sets chr6.1401A and B) there was approximately $1 \mathrm{hr}$ difference in replication time between the two synchronizations that were tested indicating that there were some experimental differences in the two isolations of replicating DNA. Our ability to determine a specific replication time for nearly all of the markers that we tested is consistent with our previous studies on chromosome 1p36 [32], and in studies reported by others [33-35], but is in sharp contrast to the results of replication timing experiments reported by Jeon et al. [21]. In replication timing studies reported by this group they found that $60 \%$ of the sequences that they tested replicated throughout the S phase. Looking at their data, we did observe that there seems to be something unusual about the replication dynamics in the HeLa cells that they used. We noticed that the S phase in these cells lasted 10 hrs, with a peak of DNA synthesis found at six hrs. In our experience with normal diploid human fibroblasts, $S$ phase lasts about $8 \mathrm{hrs}$, peaking at about $4 \mathrm{hrs}$ into $S$ phase [32]. Indeed, the possibility that the pan-replication pattern that was found in $60 \%$ of the sequences that were tested Jeon et al. was a characteristic of cancer cells was pointed out by the authors themselves. It should be noted however, that not all cancer cells have this pan-replication pattern since Tenzen et al. [34] were able to obtain discrete replication times for markers in myeloid leukemia cells.

We tested nine markers from five islands that overlap with sequences that have Woodfine replication timing ratios of 1.72 and higher $[18,19]$. Seven out of nine of these markers replicated in the first hour of S phase, the other two replicated in the second hour indicating that there was good agreement in replication time for fibroblasts and lymphoblastoid cells in the earliest replicating sequences. White et al. [20], who compared their fibroblast replication timing on chromosome 22 to the Woodfine et al. data [19], found similar results. Also, Janoueix-Lerosey et al. [36], who studied replication timing in neuroblastoma cells found that $60 \%$ of early replicating sequences also replicated early in lymphoblastoid cells. 
Table 2: PCR markers analyzed and their replication timing.

\begin{tabular}{|c|c|c|c|c|}
\hline Primer set name & Sequence & Product range & Replication time in hrs' (fibroblasts) & Woodfine replication timing ratio ${ }^{2}$ \\
\hline chr6.1385A & $\begin{array}{l}\text { F ctcagctttccctgttaatg } \\
\text { R ggaagatgctaaatgactgc }\end{array}$ & $30904535-30904712$ & 1.0 & 1.73 \\
\hline chr6.1385B & $\begin{array}{l}F \text { ggaattaaggcgtgtatctg } \\
R \text { aacttcccatagggattagc }\end{array}$ & $31023340-31023694$ & 1.5 & 1.63 \\
\hline chr6.1386A & $\begin{array}{l}F \text { agtaaatccgggtctctagg } \\
R \text { ccagatagaggcactgagag }\end{array}$ & $32021221-32021449$ & 1.0 & 1.74 \\
\hline chr6.1386B & $\begin{array}{l}\mathrm{F} \text { aaatgtccttcaccatcaag } \\
\mathrm{R} \text { attatcagagcagcaaaagg }\end{array}$ & $32151938-32152179$ & 0.9 & 1.74 \\
\hline chr6.1395A & $\begin{array}{l}\mathrm{F} \text { atgactcatgtagggcagac } \\
\mathrm{R} \text { aaggaggaacaagaggaaac }\end{array}$ & $40489161-40489555$ & 5.6 & 1.36 \\
\hline chr6.1395B & $\begin{array}{l}F \text { gtccaagctaagtccatgag } \\
R \text { gatgacaaacatgaatgcag }\end{array}$ & $4056044 I-40560763$ & 5.5 & 1.25 \\
\hline chr6.1395C & $\begin{array}{l}\mathrm{F} \text { taggtcagttgacccatctc } \\
\mathrm{R} \text { cgtgttcagtgtgtatttgc }\end{array}$ & $40601430-40601688$ & 5.4 & 1.58 \\
\hline chr6.I40IA & $\begin{array}{l}F \text { caggcccatacttcttgtag } \\
R \text { gtgagagcttctccttgatg }\end{array}$ & $43|25237-43| 25402$ & 1.6 & 1.73 \\
\hline chr6.I40IB & $\begin{array}{l}F \text { tggttcttctctccagtttg } \\
R \text { taggtgaggacacaagatcc }\end{array}$ & $43237884-43238178$ & 2.1 & 1.73 \\
\hline chr6.1417A & $\begin{array}{l}F \text { cagtagtgtgtgcacctgtc } \\
R \text { tccctgtaacttcaaccatc }\end{array}$ & $89898270-89898634$ & 4.6 & 1.51 \\
\hline chr6.1417B & $\begin{array}{l}\mathrm{F} \text { taaccccactctgtgttagg } \\
\mathrm{R} \text { cctatggagtcagagattgc }\end{array}$ & $8996348 I-89963615$ & 4.8 & 1.51 \\
\hline chr22.1096A & $\begin{array}{l}\text { F agggtcacatctacagttgg } \\
R \text { ccatttgctgtcctttctac }\end{array}$ & $23|23485-23| 236||$ & 1.1 & 1.85 \\
\hline chr22.1096B & $\begin{array}{l}\mathrm{F} \text { aatcctcctgagaattaggc } \\
\mathrm{R} \text { caggagtaatgcccacttag }\end{array}$ & 23239758-23239902 & 0.5 & 1.72 \\
\hline chr22.1102A & $\begin{array}{l}F \text { tcaggaggagtttcacattc } \\
R \text { cacagaagactcagggagag }\end{array}$ & $26718830-26718968$ & $1.0,5.0$ & 1.58 \\
\hline chr22.1102B & $\begin{array}{l}\text { F gctaggacctgaactcacac } \\
\mathrm{R} \text { tttaaagggctgctctattg }\end{array}$ & $26841004-26841279$ & 5.6 & 1.55 \\
\hline chr22.1110A & $\begin{array}{l}\mathrm{F} \text { gccctgagatactgactctg } \\
\mathrm{R} \text { aaatgcagaatgaagtggag }\end{array}$ & $31334872-31335235$ & 1.0 & 1.55 \\
\hline chr22.1IIOB & $\begin{array}{l}\text { F gacattgctcttgcctctac } \\
\text { R cttctcaagggtgtaaatgg }\end{array}$ & $3|44| 4|9-3| 44 \mid 684$ & 1.0 & 1.54 \\
\hline chr22.1112A & $\begin{array}{l}F \text { caggcatctgaaattaaacc } \\
R \text { agattagaggctggttttcc }\end{array}$ & $32486488-32486736$ & 6.0 & 1.68 \\
\hline chr22.1III2B & $\begin{array}{l}F \text { actgagattcaaccagagc } \\
R \text { agggaaacttggtaatagcc }\end{array}$ & $32533028-32533232$ & 6.1 & 1.64 \\
\hline chr22.1118 & $\begin{array}{l}\mathrm{F} \text { ttcagggtctggttggtagg } \\
\mathrm{R} \text { agcaggagactggcacagat }\end{array}$ & $3807 \mid 800-38072021$ & 0.8 & 1.99 \\
\hline chr22.1118B & $\begin{array}{l}\mathrm{F} \text { gtggggtgcactgttactat } \\
\mathrm{R} \text { atcagggacacgtaacaac }\end{array}$ & $38181333-38181482$ & 0.8 & 1.95 \\
\hline
\end{tabular}

I- Data derived from the average replication time from two synchronizations.

2- Data derived from lymphoblastoid cells (Woodfine et al. [18, 19]).

3- Primer is located $25 \mathrm{~kb}$ upstream of island in an adjacent clone.

Although our library is enriched in early replicating DNA as mentioned previously, it does contain a small fraction of middle and late replicating sequences. For example, we used two PCR primer sets to test two points in an island that overlaps a Woodfine marker with a replication ratio of 1.51. In our assay, we found that this island replicates between 4.6 and 4.8 hrs, just past the middle of S phase. Another island, also tested for replication timing, was one of the few that were very late replicating, with a replication time of 5.6 and 5.5 hrs and overlapping markers with Woodfine replication ratio of 1.36 and 1.25 . While these markers correlated well with data from lymphoblastoid cells, this did not hold true for all markers tested in fibroblasts. For example, clone island chr22.1110 overlaps markers with Woodfine replication ratios of 1.55 and 1.55 , but testing of two PCR markers in this island indicated that in fibroblasts it replicated in the first hour, not in the middle of $S$ phase. Additionally, PCR marker
chr6.1395C, which is located in a region with a replication timing ratio of 1.58 , replicates at $5.4 \mathrm{hrs}$, as do primer sets $A$ and $B$ from that same island that have Woodfine replication ratios of 1.36 and 1.25 . These differences in timing might be the result of differences in cell type and could reflect differences in gene expression and/or chromatin condensation [22] between lymphoblastoid and fibroblast cells.

\section{Distribution of repetitive elements in early replicating DNA}

As mentioned previously, SINE repetitive elements were found to be enriched in early replicating regions while there was a paucity of LINE elements in these regions, as compared to the genome as a whole. Islands were evaluated for the presence of these and several other repetitive elements as compared to all non-overlapping $100 \mathrm{~kb}$ windows across the genome. Table 3 lists those elements 


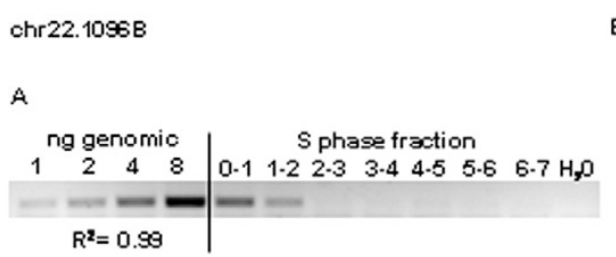

ohr $6.1385 \mathrm{~B}$

A

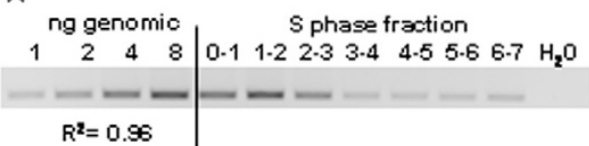

chr6.1417A

A

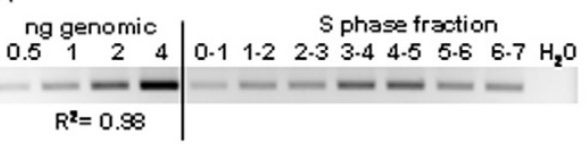

B
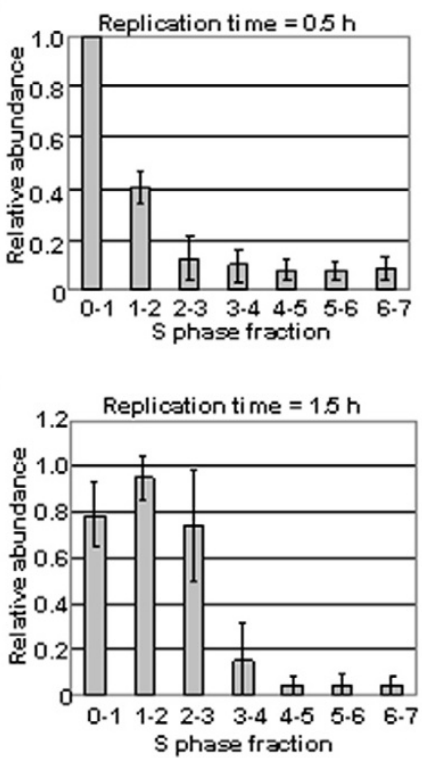

B

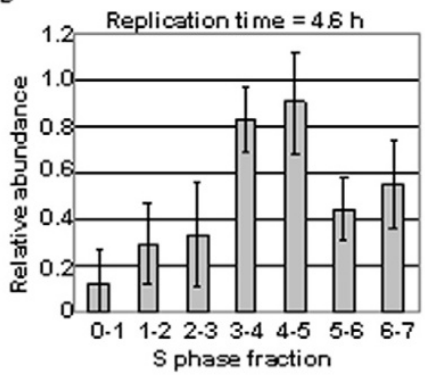

\section{Figure 3}

Determination of the timing of replication of genetic markers by PCR. The three composite panels illustrate the procedure used for determining which of seven samples of DNA, each replicated at a different I-h period of the $S$ phase, was enriched for copies of a particular marker. DNA replicated at the indicated I-h intervals of the $S$ phase of synchronized fibroblasts was labeled with BrdUrd and isolated by $\mathrm{CsCl}$ centrifugation. In each panel, A: Inverted contrast image of PCR products stained with ethidium bromide after gel electrophoresis. The same primer set was used to amplify increasing amounts of genomic DNA and DNA replicated during each of the first 7 $h$ of the S phase; a control with no template DNA was included in every PCR experiment. The $R^{2}$ value for each standard curve that was obtained by plotting the signal intensity of the bands of PCR products in the gel above versus the amount of genomic DNA, is shown. B: Bar graph illustrating the abundance of the marker in each of the seven I-h samples of the $S$ phase. Results show the average of two synchronizations that were each tested at least twice. Vertical bars indicate the standard deviation for each time point. Relative abundance was calculated from the linear regression equation of the standard curve and expressed as a percentage of the $S$ phase fraction with the highest value. Replication times were calculated as described in the Methods section. The three panels shown illustrate the results obtained with markers that replicate in the first hour of the S phase (primer chr22.1096B), during the second hour (chr6.I385B), and at $4.6 \mathrm{hrs}$ into $\mathrm{S}$ phase (chr6.14I7A).

whose content is significantly different in islands compared to the genome as a whole (as described in the Methods section). Both of the major SINE elements, Alu and mammalian-wide interspersed repeats (MIR), and L1 LINE elements were found to be distributed differently between clone islands and genomic DNA, while L2 elements were not. Four major classes of repeats that had not been investigated previously for replication timing distribution were examined here. LTR retrotransposons (mammalian LTR [MaLR], endogenous retrovirus 1 and L [ERV1 and ERVL]), DNA transposons, and low complexity repeats, were found less frequently in islands, similar to L1 elements. Alternatively, tandem repeats were found more frequently in islands. We then specifically looked at islands that overlapped markers distributed at $\sim 1 \mathrm{Mb}$ across the genome that were tested by Woodfine et al. [19] for replication timing, especially those that replicated early in the S phase. As shown in Table 3, the trends in repeat feature distributions found for all islands are even more pronounced in the islands that overlap with markers having replication timing ratios of 1.65 and higher. For example, Alu sequences are found most frequently in 
Table 3: Genomic features significantly different in islands compared with whole genomic DNA.

\begin{tabular}{|c|c|c|c|c|c|}
\hline \multirow[b]{2}{*}{ Feature } & \multirow[b]{2}{*}{ Genome } & \multirow[b]{2}{*}{ All Islands } & \multicolumn{3}{|c|}{ Islands that overlap with replication timing markers I } \\
\hline & & & $\begin{array}{l}\text { Islands with } a \geq \\
\text { I.65-timing ratio }\end{array}$ & Islands with $a \geq 1.75$-timing ratio' & Islands with $a \geq 1.85$-timing ratio' \\
\hline I 00-kb windows & 28358 & 1749 & 228 & 144 & 78 \\
\hline Genes & 30078 & 2815 & 606 & 428 & 252 \\
\hline Genes/I00 kb & 1.06 & 1.60 & 2.66 & 2.97 & 3.23 \\
\hline Promoters $^{2}$ & 10415 & 948 & 223 & 170 & 111 \\
\hline Promoters/ / 00 kb & 0.37 & 0.55 & 0.98 & 1.18 & 1.42 \\
\hline Transcribed & $37.61 \%$ & $43.73 \%$ & $56.37 \%$ & $55.88 \%$ & $54.79 \%$ \\
\hline Translated & $1.11 \%$ & $1.81 \%$ & $3.08 \%$ & $3.42 \%$ & $3.35 \%$ \\
\hline CpG_Islands & $1.94 \%$ & $4.05 \%$ & $5.20 \%$ & $5.83 \%$ & $6.58 \%$ \\
\hline CpG_Content & $1.96 \%$ & $2.76 \%$ & $3.39 \%$ & $3.63 \%$ & $3.86 \%$ \\
\hline GC_Content & $40.88 \%$ & $45.51 \%$ & $48.71 \%$ & $49.82 \%$ & $50.52 \%$ \\
\hline Conserved & $4.83 \%$ & $5.78 \%$ & $7.18 \%$ & $7.50 \%$ & $7.86 \%$ \\
\hline All_Repeats & $48.52 \%$ & $45.68 \%$ & $44.23 \%$ & $44.78 \%$ & $46.21 \%$ \\
\hline SINE & $13.67 \%$ & $17.18 \%$ & $23.28 \%$ & $25.05 \%$ & $27.71 \%$ \\
\hline Alu & $10.75 \%$ & $13.54 \%$ & $18.99 \%$ & $20.66 \%$ & $23.59 \%$ \\
\hline MIR & $2.92 \%$ & $3.64 \%$ & $4.29 \%$ & $4.39 \%$ & $4.11 \%$ \\
\hline LINE & $21.10 \%$ & $15.94 \%$ & $11.55 \%$ & $10.73 \%$ & $10.06 \%$ \\
\hline LI & $17.48 \%$ & $12.27 \%$ & $7.83 \%$ & $6.97 \%$ & $6.53 \%$ \\
\hline LTR & $8.71 \%$ & $7.45 \%$ & $5.28 \%$ & $4.98 \%$ & $4.65 \%$ \\
\hline MaLR & $3.79 \%$ & $3.30 \%$ & $2.37 \%$ & $2.34 \%$ & $2.18 \%$ \\
\hline ERVI & $3.00 \%$ & $2.58 \%$ & $1.76 \%$ & $1.66 \%$ & $1.51 \%$ \\
\hline ERVL & $1.61 \%$ & $1.32 \%$ & $0.85 \%$ & $0.75 \%$ & $0.71 \%$ \\
\hline DNA transposons & $3.02 \%$ & $2.71 \%$ & $2.35 \%$ & $2.23 \%$ & $2.02 \%$ \\
\hline MER2_type & $1.06 \%$ & $0.79 \%$ & $0.63 \%$ & $0.55 \%$ & $0.54 \%$ \\
\hline Mariner & $0.10 \%$ & $0.07 \%$ & $0.04 \%$ & $0.04 \%$ & $0.03 \%$ \\
\hline Low_complexity & $0.58 \%$ & $0.54 \%$ & $0.51 \%$ & $0.50 \%$ & $0.49 \%$ \\
\hline Tandem_Repeats & $1.82 \%$ & $2.64 \%$ & $2.1 \%$ & $2.24 \%$ & $2.44 \%$ \\
\hline
\end{tabular}

I- Replication timing ratio determined by Woodfine et al. [19].

2- Active promoters in IMR90 fibroblasts as determined by Kim et al. [44].

islands overlapping markers with replication timing ratios $\geq 1.85$.

As mentioned above, tandem repeats, which included micro- and mini-satellites, were found enriched in islands. It has been established previously that tandem repeats are distributed in a nonrandom manner, with most being found in non-coding DNA and in both intergenic regions and introns [37]. This is probably due, with the exception of tri- and hexa-nucleotide repeats, to selection against frameshift mutations [37]. An excess of tandem repeats in early replicating DNA however, has not been reported previously. Some of this enrichment may be linked to the other repetitive elements that are enriched in early replicating sequences. For example, Alu repeats often contain microsatellite-like regions at their 3 ' ends [38]. Since we found an enrichment of Alu sequences in islands, this could explain some of the enrichment of certain types of A-rich microsatellite structures. To determine whether A-rich microsatellites were responsible for the enrichment, we looked at the distribution of individual classes of tandem repeats in islands. This included mono, di-, tri-, tetra-, penta-, and hexa-nucleotide repeats, as well those with a periodicity of greater than six bases [see Additional file 1]. We found that all classes of tandem repeats, except di-nucleotides, were present at a higher level in islands than in the genome as a whole. Di-nucleotide repeats were actually found to be slightly depleted in islands. It is not clear why di-nucleotide repeats do not follow the same early replicating trend as other tandem repeats. Changes in the length of and presumably the establishment of microsatellites are thought to be caused primarily by DNA slippage during replication [39]. This mechanism would involve increases in the length of short, and decreases in the length of long tandem repeats [40]. Most of these changes are corrected by the mismatch repair pathway [41]. It is possible that there are differences in the process that causes slippage mutations [40], or the ability to repair, the different classes of tandem repeats. These differences would presumably be influenced by the genomic features associated with early replicating sequences. 


\section{Open chromatin in early replicating regions}

Using the same $1 \mathrm{Mb}$ clone microarray as Woodfine et al. [19], Gilbert et al. [22] determined ratios for the enrichment of open (positive) regions of chromatin for each marker. Sites that were depleted in open chromatin sequences were considered to be regions of more compact (negative) chromatin. Lymphoblastoid cells were used in the Gilbert et al. [22] study and chromatin conformation most certainly differs between fibroblasts and lymphoblastoid cells in select regions. Nonetheless, we hypothesized that the overall chromatin conformation should be similar in both cell types. Gilbert et al. [22] previously reported a good correlation between open chromatin and early replication, based on the replication timing results of the $1 \mathrm{Mb}$ array reported by Woodfine et al. [19]. They note, however, that except in the regions with the highest enrichment in open chromatin, this correlation diminishes when chromatin data is compared to the high-resolution replication data on 22q. Gilbert et al. [22] suggested that, since there were a multitude of sites that were not enriched in open chromatin but were nevertheless early replicating, the two physiological characteristics (open chromatin and early replication) were not functionally related.

We investigated islands that overlapped the same $1 \mathrm{Mb}$ markers tested by Gilbert et al. [22] for chromatin confirmation and determined that over two-thirds of islands were found in an open state (log2 open $>0$, as determined by Gilbert et al. [22]) as detailed in Table 4. In addition, among islands that overlapped markers with replication timing ratios $\geq 1.85$ (as determined by Woodfine et al. [19]), over 90\% corresponded to regions enriched in open chromatin. In contrast, less than half of all genome-wide $100 \mathrm{~kb}$ windows that overlapped array markers were determined to be in an open state. To assess how well an open chromatin state predicts early replication, we analyzed the 100 markers that were determined by Gilbert et al. [22] to have the highest $\log 2$ open ratios and found that 38 directly overlapped an island. Another 23 overlap a single early replicating clone, and 15 were within $50 \mathrm{~kb}$ of an island or clone. In contrast, among the 100 arrayed markers with the lowest log2 open ratios, only eight overlapped an island, 19 overlapped a single early replicating clone, and nine were within $50 \mathrm{~kb}$ of an island or clone. Over half of this mostly closed chromatin group was greater than $100 \mathrm{~kb}$ from the nearest early replicating clone. These data would seem to indicate, therefore, that the most open sequences are correlated with early replication, in agreement with the results reported by Gilbert et al. [22] for the $1 \mathrm{Mb}$ array markers.

We also investigated regions of $22 \mathrm{q}$ where a total of 28 islands overlapped markers from the high-resolution array where the Woodfine et al. [19] data suggested an early replication time (replication ratio $\geq 1.75$ ) and where chromatin data was also available [22]. Since our islands average $100 \mathrm{~kb}$ in length and the spacing of clones on this array averages $70 \mathrm{~kb}$, it is not unusual for an island to overlap more than one array marker. Together, the 28 islands overlapped 20 markers found to be in a more closed chromatin state $(\log 2$ open $<0)$ and 26 markers in an open state $(\log 2$ open $>0)$. Based on this data using markers from the high-resolution array, there is clearly little correlation between early replication and open chromatin as noted by Gilbert et al. [22]. However, this lack of correlation could be attributed to a difference in the cell types, and thus chromatin states, at these locations in lymphoblastoid and fibroblast cells. Our data from chromosome 22 indicates another possible explanation. We found that 20 of the 28 islands (71\%) overlapped at least one marker with $\log 2$ open $>0$, but some also overlapped an additional marker with $\log 2$ open $<0$. An example of this type of distribution occurred with island chr22.1090, which was defined by 6 separate early replicating clones, is $140 \mathrm{~kb}$ in length, and overlapped three arrayed markers with $\log 2$ open chromatin ratios of $-0.538,0.435$, and 0.951. It is possible in these instances that an origin of replication that fires early in the $S$ phase may be contained in the region of open chromatin, and fork progression from this origin extends into the nearby regions of more compact chromatin. Identification of replication origins and replicon boundaries in these regions will help to determine if this is indeed the case.

\section{Transcription and early replication}

Islands were evaluated for features related to transcription. Islands had a higher gene density, and were enriched

Table 4: Chromatin structure and replication timing. Chromatin ratios were determined by Gilbert et al. (2004).

\begin{tabular}{lccc}
\hline & I00-kb windows & Average Chromatin Ratio & Regions of Open Chromatin \\
\hline Genome & 6852 & -0.0396 & $3230(47.1 \%)$ \\
All Islands & 461 & 0.3482 & $309(67.0 \%)$ \\
Islands with a $\geq$ I.65-timing ratio' & 194 & 0.6374 & $158(81.4 \%)$ \\
Islands with a $\geq$ I.75-timing ratio' & 130 & 0.7983 & $112(86.1 \%)$ \\
Islands with a $\geq$ I.85-timing ratio' & 73 & 0.8993 & $66(90.4 \%)$ \\
\hline
\end{tabular}

I. Replication timing ratio determined by Woodfine et al. [19]. 
in transcribed and translated sequences as compared to the whole genome (Table 3). A correlation between early replication and actively transcribed regions has been previously established $[19,42]$. It is, therefore, not surprising that CpG islands, CpG content, and GC content are also found at higher densities in early replicating DNA, as each of these parameters are related to gene density. Likewise, we found that islands had greater amounts of evolutionarily conserved elements ([43]; [see Additional file 2]) that are also predominately associated with gene sequences.

In a recent report, Kim et al. [44] evaluated the transcriptional status of promoters in human fibroblasts (IMR90 cells) by analyzing these sequences for the binding of the RNA polymerase II preinitiation complex. Here, we evaluated the distribution of active promoters [44] in early replicating DNA islands. As expected, active promoter density is greater in the islands as compared to the genome as a whole. Again, differences in feature content are even greater when considering only the subset of islands that overlap markers tested by Woodfine et al. [19] with replication timing ratios of $\geq 1.65$ (Table 3 ).

\section{Functional analysis of early replicating genes}

Although it has been known that expressed genes, especially house-keeping genes, replicate predominately in the first half of S phase [42], these studies have not defined with great accuracy how early in S phase they replicate nor which genes are replicated in successive cohorts. In the present study, we were able to examine this question with greater precision. We looked at genes associated with islands and found that nine (47\%) of the 19 WNT genes (wingless-type MMTV integration site family) were present. The nine island-associated WNT genes were located in eight islands found on eight different chromosomes. This family of genes is involved in stem cell regulation, wound healing in dermal fibroblasts, and is associated with cancer in many tissue types [45]. Islands were enriched in genes associated with DNA repair, especially those related to the base excision repair pathway $[46,47]$. These include four of ten known human DNA glycosylases (MBD4, NTH1, MPG and NEIL2), and several genes involved in the repair of apurinic/apyrmidinic sites (XRCC1, POLB, POLL, PARP1, FEN1, and RPA3). MGMT, whose gene product directly repairs $\mathrm{O}^{6}$-methylguanines, is also associated with a library island. A complete list of genes associated with library islands can be found in Additional file 3.

To evaluate further the potential function of genes that were associated with the islands we used the GOstat program $[48,49]$. This program uses the information in the Gene-Ontology (GO) database to generate statistical information on which categories of genes are over or underrepresented in a given list of genes. Results are shown in Table 5. From a total of 3265 unique islandassociated genes UCSC Known Genes dataset [29], 1975 genes were assigned to functional categories. Several categories were over or underrepresented in comparison to the full UCSC Known Genes dataset. Overrepresented categories included cell death/apoptosis and the frizzled-2 (WNT) signaling pathway. Pro-apoptotic genes found associated with the library function in all aspects of the apoptotic process, and include FAS, TRAF7, BID, BAD, $B A X, C A S P 3$, and CASP8. Anti-apoptotic genes included BCL2, TRAF1, and TRAF2. The overrepresentation of genes in both the WNT and apoptotic pathways in islands is interesting since these two pathways function together for morphogenesis during development and for tissue homeostasis in differentiated cells (reviewed in [50]). For example, some WNTs can inhibit apoptosis through the $\beta$ catenin/T-cell factor transcription mediated pathway. This inhibition of apoptosis has been shown for a variety of cell types including fibroblasts [51]. Underrepresented gene categories included rhodopsin-like and olfactory receptors. These are tissue specific genes that are not known to be expressed in dermal fibroblasts and therefore, were not expected to be found in early replicating DNA from these cells.

Our previous studies showed that cells in the earliest part of the $S$ phase of the cell cycle are most vulnerable to malignant transformation by chemical carcinogens [5254]. We hypothesized that the vulnerability of cells at the start of the $S$ phase to carcinogen-induced changes that lead to cancer is due to the increased probability of mutating a relevant genetic target (whether a cancer gene or a regulatory region) during its replication at the time of carcinogen treatment early in the S phase. The finding that apoptotic, WNT genes, and DNA repair genes replicate in this compartment of the $\mathrm{S}$ phase, therefore, provides novel information on possible targets for carcinogenesis that are consistent with previous reports for common alterations in cancer.

We also examined the distribution of gene ontology categories for replication timing data reported for lymphoblastoid cells by Woodfine et al. [18,19]. We found that markers used in these studies $[18,19]$ overlapped with 9000 genes in the Known Gene dataset. For GOstat analysis, markers tested by Woodfine et al. $[18,19]$ were separated into three bins based on replication timing ratios: > 1.75 (very early; 3213 genes), 1.5-1.75 (early; 2698 genes), < 1.5 (late; 3093 genes). Genes that mapped to each bin were then compared to the complete set of 9000 genes. Results for over and underrepresented functional categories for each replication-timing bin are listed in Table 5 along with the GOstat results for islands. For GO hierarchies where multiple ontologies were overrepre- 
Table 5: GOstat results. Representation of different GO functional categories as determined by the GOstat program [48].

\begin{tabular}{|c|c|c|c|c|}
\hline \multirow[b]{2}{*}{ Function } & \multirow[b]{2}{*}{ Islands } & \multicolumn{3}{|c|}{ Woodfine replication markers 1} \\
\hline & & $>1.75$ & $1.75-1.5$ & $<1.5-1.25$ \\
\hline Apoptosis (programmed cell death) & over & over & & \\
\hline Frizzled-2 (WNT) signaling pathway & over & & & \\
\hline Intracellular ligand-gated ion channel activity & over & & & \\
\hline Transmembrane receptor protein tyrosine kinase activity & over & & & \\
\hline Transmembrane receptor protein tyrosine phosphatase activity & over & & & \\
\hline G-protein coupled receptor activity & under & under & & over \\
\hline Rhodopsin-like receptor activity & under & under & & over \\
\hline G-protein coupled receptor protein signaling pathway & under & under & under & over \\
\hline Olfactory receptor activity & under & & under & over \\
\hline Sensory perception of smell & under & & under & over \\
\hline Proteasome complex (sensu Eukaryota) & & over & & \\
\hline Cation-transporting ATPase activity & & over & & \\
\hline Positive regulation of signal transduction & & over & & \\
\hline Lipid biosynthesis & & over & & \\
\hline Lipid metabolism & & over & & \\
\hline Intracellular protein transport & & over & & \\
\hline Receptor signaling protein activity & & over & & \\
\hline Regulation of transcription factor activity & & over & & \\
\hline Protein binding ${ }^{2}$ & & over & & under \\
\hline Positive regulation of cellular process & & over & & under \\
\hline Intracellular membrane-bound organelle & & over & & under \\
\hline Cell surface receptor linked signal transduction & & under & under & over \\
\hline Transmembrane receptor activity & & under & & over \\
\hline Neurophysiological process & & under & & over \\
\hline Nucleosome assembly & & under & over & \\
\hline DNA binding & & & over & \\
\hline DNA metabolism & & & over & \\
\hline Antigen processing endogenous antigen via $\mathrm{MHC}$ class $\mathrm{I}^{2}$ & & & over & \\
\hline MHC class I protein complex ${ }^{2}$ & & & over & \\
\hline MHC class I receptor activity ${ }^{2}$ & & & over & \\
\hline Calcium-mediated signaling & & & over & \\
\hline Calcium ion binding & & & under & \\
\hline Carbohydrate binding & & & under & \\
\hline Muscle contraction & & & under & \\
\hline Integral to membrane & & & under & over \\
\hline Phosphoric ester hydrolase activity & & & & over \\
\hline Organismal physiological process & & & & over \\
\hline Cell communication & & & & over \\
\hline Glutamate signaling pathway & & & & over \\
\hline Keratin filament & & & & over \\
\hline Sensory perception of taste & & & & over \\
\hline Positive regulation of cellular metabolism & & & & under \\
\hline
\end{tabular}

I- Replication timing ratios determined by Woodfine et al. [18, 19].

2 - Indicates functional categories overrepresented in genes associated with Woodfine et al. $([18,19])$ timing markers. 
sented, the most specific member was listed. Complete results for GOstat analysis of islands and Woodfine replication markers can be found in Additional file 4. It should be noted that there were several functional categories that were overrepresented in the original set of genes that overlapped with Woodfine replication markers (Table 5). These categories were associated primarily with the major histocompatability complex (MHC) that is found on chromosome 6 where the replication timing markers were placed at high density as described previously [18].

As shown in Table 5, there are some overrepresented categories that are found in island DNA but not in any of the bins of replication markers tested in lymphoblastoid cells. One reason for this may simply be the position of replication markers tested by Woodfine et al. $[18,19]$ since these markers were not randomly distributed throughout the genome. For example, only four of the 19 WNT genes overlap with these markers, which would make it difficult to determine whether they were overrepresented in any replication timing bin. It is also possible that the way that we partitioned these markers into bins obscured some GOstat results.

Temporal replication patterns for functionally related genes have been shown previously for the $\beta$-globin [55] and immunoglobulin heavy-chain locus gene clusters [5] but not for genes dispersed throughout the genome. The GOstat results in Table 5 give us an indication that there are temporal patterns of replication for some functionally related genes. Apoptotic genes for example, are overrepresented in both islands and the earliest replicating fraction from lymphoblastoid cells. This finding leads us to believe that genes involved in apoptosis represent a subset of genes that have been selected to replicate very early in the S phase. Another example of a functional group of genes that replicate at about the same time are genes involved in nucleosome assembly. These genes replicate predominately in the second quarter of S phase based on replication timing ratios reported by Woodfine et al. $[18,19]$. This time of replication overlaps with the time when histone genes are being actively transcribed; histone transcription levels increase at the onset of $S$ phase but reach their peak at about mid way through S phase [56].

\section{Conclusion}

In summary, in this work we present a genome-wide method for the identification of sequences that replicate early in the $\mathrm{S}$ phase. This method relied on the isolation and cloning of early replicating sequences followed by the end-sequencing and mapping of these clones to the nearly complete human genome sequence. This allowed us to evaluate regions with overlapping clones that are similar in size to an average replicon and therefore should replicate at the same time in $\mathrm{S}$ phase. This method has the advantage over microarray studies of replication timing in that there should be less contamination from adjacent sequences when trying to identify genomic features that correlate with time of replication. We found that for the earliest replicating sequences in normal human fibroblasts, there is a positive correlation with open chromatin, gene and exon density, and active promoters. Based on our comparison of replication timing in fibroblast and lymphoblastoid cells, these regions are more likely to replicate at the same time in multiple cell types than sequences that replicate at other times in the $S$ phase. In addition, there are a few subsets of functionally related genes, including those for apoptosis and WNT signaling, that are replicated at this time. All of these data suggest that the chromatin structure/gene composition of this compartment of the $\mathrm{S}$ phase is conserved and may be important for the maintenance of cell stability and if defective may confer genetic instability. We are currently in the process of identifying origins of replication and replicon boundaries in some of these very early replicating regions in order to understand further the processes that orchestrate the order of replication at the beginning of the $S$ phase.

\section{Methods \\ Flow cytometry}

NHF1 cells were synchronized and incubated in BrdUrd for $24 \mathrm{hrs}$ in the presence of aphidicolin as described above. After collection by trypsinization, cells were washed and resuspended in cold saline, fixed in $67 \%$ ethanol, then stained with propidium iodide and fluorescein isothiocyanate (FITC)-conjugated anti-BrdU antibody (Becton Dickinson, Franklin Lakes, NJ) as described [57]. Flow cytometric analysis was done on a FACscan (Becton Dickinson) and the number of $S$ phase cells was quantified using WinMDI program (Joseph Trotter, Scripps laboratory, [58]).

\section{End sequencing of library clones}

Cosmid DNA template was purified in 96-well format using LigoChem ProPreps, with ProCipitate, a synthetically engineered protein-binding polyelectrolyte (modification of method described in Kelley et al. [59]). Cycle sequencing was performed using ABI Big Dye Terminator cycle sequencing kits and reactions were run on ABI 3700 or ABI 3730 sequencers.

\section{Mapping of paired cosmid clone ends to the human genome sequence}

Reads were trimmed to minimize those of low quality (Phred score $<20$ ) and to remove vector sequences prior to their alignment to the genome. Trimmed sequences were aligned to the NCBI build 35 (April 2004) sequence assembly using BLAT [28] with the default parameters except ooc $=11$. ooc and - stepSize $=5$. Resulting align- 
ments were filtered to retain only the best alignments, requiring at minimum $80 \%$ of the trimmed sequence aligning with at least $90 \%$ base pair identity. Alignments from the $5^{\prime}$ and 3 ' ends of the same cosmid clone were paired when these alignments were on the same chromosome, in the proper orientation, at a distance of at least 30 $\mathrm{kb}$ and no more than $50 \mathrm{~kb}$ from each other, consistent with sizing that is expected with cosmid cloning. These paired ends delimit the full extent of the clone in the genome sequence. Unpaired end sequences, where the pairing end sequence was either not available, could not be aligned, or was not a correct distance or orientation, were also retained as "orphan" ends. Only clones uniquely placed by paired ends or an orphan end were considered for further analysis. In addition, clones that mapped to nearly the same location as another clone and originated from an adjacent well in the 96-well plates used for sequencing, were removed as probable contaminants.

\section{Determination of early replicating islands}

Positions of early replicating clones were merged to create "islands" of early replication. Only clones within $100 \mathrm{~kb}$ of each other were merged, and the resulting island could be no longer than $175 \mathrm{~kb}$. At least two clones were required to form an island.

\section{Extraction of genomic features}

Additional file 2 lists all genomic features considered in this analysis. Except for gene and promoter counts, chromosome bands, and chromatin status, the percentage of each feature was determined for each specified genomic region. These percentages were normalized to a $100-\mathrm{kb}$ window to allow for comparison. Chromatin status was considered only for those genomic regions that overlapped a clone assayed in Gilbert et al. [22].

\section{Determination of features significantly different in two datasets}

For a feature represented by real-valued numbers for each genomic region coming from one of two distinct sets, the non-parametric Mann-Whitney/Wilcoxson ranksum test was used to calculate $z$-scores, providing a measure of the difference of the content of that feature in the two sets. To determine whether this difference was significant, 10,000 balanced permutations tests [60] were performed. Those features where no more than one of the 10,000 permutations had greater $z$-scores were considered significantly different in the two sets of sequence regions.

\section{Cell cultures, synchronization of normal human fibroblasts and isolation of replicating DNA}

NHF1-hTERT cells, the immortalized cell line derived from NHF1 cells by ectopic expression of the catalytic subunit of telomerase [61], were used for these studies.
NHF1-hTERT cells were grown in Dulbecco's modified essential medium containing $2 \mathrm{X}$ the concentration of MEM non-essential amino acids (GIBCO-BRL, Grand Island, NY). Growth media was supplemented with $2 \mathrm{mM}$ L-glutamine (GIBCO-BRL) and 10\% fetal bovine serum (HyClone Laboratories, Inc., Logan UT).

Cells uniformly labeled with ${ }^{14} \mathrm{C}$-thymidine were synchronized by a combination of confluence arrest, followed by replating at lower cell density and treatment with aphidicolin for $24 \mathrm{hr}$. After removal of the inhibitor, the cells progress through the $S$ phase as a synchronous cohort. The synchronized cells were labeled with BrdUrd and ${ }^{3} \mathrm{H}$-thymidine during sequential 1 -h periods of the $\mathrm{S}$ phase and the replicated, hybrid-density DNA was fractionated by $\mathrm{CsCl}$ gradient centrifugation [32,62]. After dialysis and concentration, the total amount of replicated DNA in the samples was determined from the specific activity of ${ }^{14} \mathrm{C}$-labeled DNA.

\section{Determination of replication timing in Brdu-labeled nascent DNA}

DNA replicated in different windows of the $S$ phase was tested for the relative abundance of selected genetic markers (Table 2). PCR primers were designed using Primer3 [63] or Prime (GCG Version 11.0, Accelrys Inc., San Diego, CA). PCR was performed using the OmnE and PCR Express thermocyclers (Thermo Electron Corporation, Waltham, MA) with Thermo-Start DNA polymerase (ABGene inc., Rochester, NY). PCR reaction conditions and, capture and analysis of digital gel images were described previously [31]. Equal amounts of replicating DNA from samples representing seven hrs of the $S$ phase were used as template for PCR reactions. In order to obtain quantitative results, it was necessary to carry out the PCR reactions under non-saturating conditions, and to construct a standard curve with genomic DNA of the same size as the tested DNA $[31,32]$. DNA used for these PCR standard curves consisted of purified human genomic DNA, which was sheared 10 times through a 21gauge needle, in the same way as the BrdU-labeled DNA prior to $\mathrm{CsCl}$ gradient centrifugation [62]. Table 2 lists data from all markers tested. A numerical value approximating the time of replication was determined for each PCR marker tested using a previously described weighted average method [32]. Briefly, a synchronized population of cells travels as a cohort through the $S$ phase with the broadness of the peak reflecting the degree of synchrony. Therefore, it is necessary to consider more than one hourly replication fraction when calculating replication time. In order to determine the replication timing for each PCR marker, we first normalized by assigning the value of one to the highest sample and scaling all the other measurements to their corresponding fraction. Then, we included in our weighted average analysis the peak repli- 
cation fraction and any other fraction that had > = to $50 \%$ of the peak value. This method while not producing an exact replication time does provide a good estimate, and allows for comparison among markers.

\section{Abbreviations}

SINE, short interspersed repeat element; LINE long interspersed repeat element; LTR, long terminal repeats; NHF1, normal human fibroblasts; BrdUrd, bromodeoxyuridine; MIR, mammalian-wide interspersed repeats; MaLR, mammalian LTR; ERV1, endogenous retrovirus 1; ERVL, endogenous retrovirus $\mathrm{L}$; WNT, wingless-type MMTV integration site family.

\section{Authors' contributions}

SC performed the PCR based replication timing studies, analyzed the results of the GOstat analysis, and drafted the manuscript. TF carried out all of the bioinformatics analyses, alignment of clone sequences, identified early replicating islands and participated in the drafting of the manuscript. ND was responsible for end-sequencing the library clones. DK was the initiator and director of this project. All authors participated in the design of this study and approved the final manuscript.

\section{Additional material}

\section{Additional file 1}

Analysis of tandem repeats associated with clone islands.

Click here for file

[http://www.biomedcentral.com/content/supplementary/1471-

2164-7-301-S1.xls]

\section{Additional file 2}

List of all genomic features analyzed.

Click here for file

[http://www.biomedcentral.com/content/supplementary/1471-

2164-7-301-S2.xls]

\section{Additional file 3}

Genes associated with clone islands.

Click here for file

[http://www.biomedcentral.com/content/supplementary/1471-

2164-7-301-S3.xls]

\section{Additional file 4}

Results of GO database analysis using the GOStat program available at http://gostat.wehi.edu.au.

Click here for file

[http://www.biomedcentral.com/content/supplementary/1471-

2164-7-301-S4.xls]

\section{Acknowledgements}

This work was support by NIH grants CA084493 and ES09I I2. We thank the DOE Joint Genome Institute for the cosmid end-sequencing.

\section{References}

I. Tribioli C, Biamonti G, Giacca M, Colonna M, Riva S, Falaschi A: Characterization of human DNA sequences synthesized at the onset of S-phase. Nucleic Acids Res 1987, I 5(24): 1021 I - 10232.

2. Edenberg HJ, Huberman JA: Eukaryotic chromosome replication. Annu Rev Genet 1975, 9:245-284.

3. Hand R: Eucaryotic DNA: organization of the genome for replication. Cell 1978, 15(2):317-325.

4. Berezney R, Dubey DD, Huberman JA: Heterogeneity of eukaryotic replicons, replicon clusters, and replication foci. Chromosoma 2000, 108(8):47I-484.

5. Hatton KS, Dhar V, Brown EH, Iqbal MA, Stuart S, Didamo VT, Schildkraut CL: Replication program of active and inactive multigene families in mammalian cells. Mol Cell Biol 1988, 8(5):2149-2। 58.

6. Jackson DA, Pombo A: Replicon clusters are stable units of chromosome structure: evidence that nuclear organization contributes to the efficient activation and propagation of $S$ phase in human cells. J Cell Biol I998, I 40(6): I285- I 295.

7. Ganner E, Evans $H J$ : The relationship between patterns of DNA replication and of quinacrine fluorescence in the human chromosome complement. Chromosoma 197I, 35(3):326-34I.

8. Dutrillaux B, Couturier J, Richer CL, Viegas-Pequignot E: Sequence of DNA replication in $277 \mathrm{R}$ - and Q-bands of human chromosomes using a BrdU treatment. Chromosoma 1976, 58(I):5I-6I.

9. Holmquist G, Gray M, Porter T, Jordan J: Characterization of Giemsa dark- and light-band DNA. Cell I 982, 3 I (I): I I - 29.

10. Yokota H, Singer MJ, van den Engh GJ, Trask BJ: Regional differences in the compaction of chromatin in human G0/GI interphase nuclei. Chromosome Res 1997, 5(3): I57-I66.

II. Sasaki T, Matsumoto T, Yamamoto K, Sakata K, Baba T, Katayose Y, Wu J, Niimura $Y$, Cheng $Z$, al. : The genome sequence and structure of rice chromosome I. Nature 2002, 420(69 I 3):3 I2-3I6.

12. Niimura $Y$, Gojobori T: In silico chromosome staining: reconstruction of Giemsa bands from the whole human genome sequence. Proc Natl Acad Sci U S A 2002, 99(2):797-802.

13. Craig JM, Bickmore WA: Chromosome bands--flavours to savour. Bioessays 1993, I5(5):349-354.

14. Sumner AT, de la Torre J, Stuppia L: The distribution of genes on chromosomes: a cytological approach. J Mol Evol 1993, 37(2): II7-I22.

15. Craig JM, Bickmore WA: The distribution of CpG islands in mammalian chromosomes. Nat Genet 1994, 7(3):376-382.

16. Chen TL, Manuelidis L: SINEs and LINEs cluster in distinct DNA fragments of Giemsa band size. Chromosoma 1989, 98(5):309-316.

17. Korenberg JR, Rykowski MC: Human genome organization: Alu, lines, and the molecular structure of metaphase chromosome bands. Cell I988, 53(3):39|-400.

18. Woodfine K, Beare DM, Ichimura K, Debernardi S, Mungall AJ, Fiegler $\mathrm{H}$, Collins VP, Carter NP, Dunham I: Replication timing of human chromosome 6. Cell Cycle 2005, 4(I): I72-I 76.

19. Woodfine K, Fiegler H, Beare DM, Collins JE, McCann OT, Young BD, Debernardi S, Mott R, Dunham I, Carter NP: Replication timing of the human genome. Hum Mol Genet 2004, I3(2): | 1 |-202.

20. White EJ, Emanuelsson O, Scalzo D, Royce T, Kosak S, Oakeley EJ, Weissman S, Gerstein M, Groudine M, Snyder M, Schubeler D: DNA replication-timing analysis of human chromosome 22 at high resolution and different developmental states. Proc Natl Acad Sci U S A 2004, I 0 I(5 I): I777I- 17776.

21. Jeon Y, Bekiranov S, Karnani N, Kapranov P, Ghosh S, MacAlpine D, Lee C, Hwang DS, Gingeras TR, Dutta A: Temporal profile of replication of human chromosomes. Proc Natl Acad Sci U S A 2005, 102(18):6419-6424.

22. Gilbert N, Boyle S, Fiegler H, Woodfine K, Carter NP, Bickmore WA: Chromatin architecture of the human genome: gene-rich domains are enriched in open chromatin fibers. Cell 2004, I I 8(5):555-566.

23. Brylawski BP, Cohen SM, Longmire JL, Doggett NA, Cordeiro-Stone $M$, Kaufman DG: Construction of a cosmid library of DNA replicated early in the $\mathbf{S}$ phase of normal human fibroblasts. J Cell Biochem 2000, 78(3):509-517.

24. Boyer JC, Kaufmann WK, Cordeiro-Stone M: Role of postreplication repair in transformation of human fibroblasts to anchorage independence. Cancer Res 199I, 5 I (I I):2960-2964. 
25. Cordeiro-Stone M, Kaufman DG: Kinetics of DNA replication in C3H IOTI/2 cells synchronized by aphidicolin. Biochemistry I985, 24( I 8):4815-4822.

26. Levenson V, Hamlin JL: A general protocol for evaluating the specific effects of DNA replication inhibitors. Nucleic Acids Res I993, 2 I (I 7):3997-4004.

27. Sorscher DH, Cordeiro-Stone $M$ : Gene replication in the presence of aphidicolin. Biochemistry I991, 30(4): 1086-1090.

28. Kent WJ, Sugnet CW, Furey TS, Roskin KM, Pringle TH, Zahler AM, Haussler D: The human genome browser at UCSC. Genome Res 2002, I 2(6):996-1006.

29. Duke mirror website of UCSC Genome Browser [http:// genome-mirror.duhs.duke.edu]

30. Furey TS, Haussler D: Integration of the cytogenetic map with the draft human genome sequence. Hum Mol Genet 2003, I 2(9): I037-1044.

31. Cohen SM, Brylawski BP, Cordeiro-Stone M, Kaufman DG: Mapping of an origin of DNA replication near the transcriptional promoter of the human HPRT gene. J Cell Biochem 2002, 85(2):346-356.

32. Brylawski BP, Cohen SM, Horne H, Irani N, Cordeiro-Stone $M$, Kaufman DG: Transitions in replication timing in a 340 kb region of human chromosomal R-Band Ip36.I. J Cell Biochem 2004, 92(4):755-769.

33. Strehl S, LaSalle JM, Lalande M: High-resolution analysis of DNA replication domain organization across an $\mathbf{R} / \mathbf{G}$-band boundary. Mol Cell Biol 1997, I7(1 0):6157-6166.

34. Tenzen T, Yamagata T, Fukagawa T, Sugaya K, Ando A, Inoko H, Gojobori T, Fujiyama A, Okumura K, Ikemura T: Precise switching of DNA replication timing in the $\mathrm{GC}$ content transition area in the human major histocompatibility complex. Mol Cell Biol 1997, I 7(7):4043-4050.

35. Watanabe $Y$, Tenzen T, Nagasaka $Y$, Inoko H, Ikemura T: Replication timing of the human $X$-inactivation center $(X I C)$ region: correlation with chromosome bands. Gene 2000, 252(I2): $163-72$.

36. Janoueix-Lerosey I, Hupe P, Maciorowski Z, La Rosa P, Schleiermacher G, Pierron G, Liva S, Barillot E, Delattre O: Preferential Occurrence of Chromosome Breakpoints within Early Replicating Regions in Neuroblastoma. Cell Cycle 2005, 4( I 2):.

37. Metzgar D, Bytof J, Wills C: Selection against frameshift mutations limits microsatellite expansion in coding DNA. Genome Res 2000, I 0(I):72-80.

38. Arcot SS, Wang Z, Weber JL, Deininger PL, Batzer MA: Alu repeats: a source for the genesis of primate microsatellites. Genomics 1995, 29(I): | 36-| 44

39. Tachida $H$, lizuka $M$ : Persistence of repeated sequences that evolve by replication slippage. Genetics 1992, I 3 I (2):47| -478.

40. Lai $Y$, Sun F: The relationship between microsatellite slippage mutation rate and the number of repeat units. Mol Biol Evol 2003, 20( I 2):2|23-2I3|.

4I. Boyer JC, Umar A, Risinger JI, Lipford JR, Kane M, Yin S, Barrett JC, Kolodner RD, Kunkel TA: Microsatellite instability, mismatch repair deficiency, and genetic defects in human cancer cell lines. Cancer Res 1995, 55(24):6063-6070.

42. Holmquist GP: Role of replication time in the control of tissuespecific gene expression. Am J Hum Genet 1987, 40(2): I5I-I73.

43. Siepel A, Bejerano G, Pedersen JS, Hinrichs AS, Hou M, Rosenbloom K, Clawson H, Spieth J, Hillier LW, Richards S, Weinstock GM, Wilson RK, Gibbs RA, Kent WJ, Miller W, Haussler D: Evolutionarily conserved elements in vertebrate, insect, worm, and yeast genomes. Genome Res 2005, I 5(8): I034-1050.

44. Kim TH, Barrera LO, Zheng M, Qu C, Singer MA, Richmond TA, Wu Y, Green RD, Ren B: A high-resolution map of active promoters in the human genome. Nature 2005, 436(7052):876-880.

45. Reya $T$, Clevers $H$ : Wnt signalling in stem cells and cancer. Nature 2005, 434(7035):843-850.

46. Wood RD, Mitchell M, Lindahl T: Human DNA repair genes, 2005. Mutat Res 2005, 577(1-2):275-283.

47. Krokan HE, Standal R, Slupphaug G: DNA glycosylases in the base excision repair of DNA. Biochem J 1997, 325 ( Pt I): I- I6.

48. GOstat by Tim Beissbarth [http://gostat.wehi.edu.au]

49. Beissbarth T, Speed TP: GOstat: find statistically overrepresented Gene Ontologies within a group of genes. Bioinformatics 2004, 20(9): |464-| 465 .
50. Li F, Chong ZZ, Maiese K: Winding through the WNT pathway during cellular development and demise. Histol Histopathol 2006, 2 I (I): I03-I24.

5I. Ueda Y, Hijikata M, Takagi S, Takada R, Takada S, Chiba T, Shimotohno $\mathrm{K}$ : Wnt/beta-catenin signaling suppresses apoptosis in low serum medium and induces morphologic change in rodent fibroblasts. Int / Cancer 2002, 99(5):68|-688.

52. Grisham JW, Greenberg DS, Kaufman DG, Smith GJ: Cycle-related toxicity and transformation in $10 \mathrm{TI} / 2$ cells treated with $\mathbf{N}$ methyl-N'-nitro-N-nitrosoguanidine. Proc Natl Acad Sci U S A 1980, 77(8):48I 3-48I7.

53. Kaufmann WK, Boyer IC, Smith BA, Cordeiro-Stone M: DNA repair and replication in human fibroblasts treated with (+/-)-r-7,t8-dihydroxy-t-9, I0-epoxy-7,8,9, I0-tetrahydrobenzo[a]pyrene. Biochim Biophys Acta 1985, 824(2):|46-I5I.

54. Kaufmann WK, Rice JM, Wenk ML, Devor D, Kaufman DG: Cell cycle-dependent initiation of hepatocarcinogenesis in rats by methyl(acetoxymethyl)nitrosamine. Cancer Res 1987. 47(5): $1263-1266$

55. Kitsberg D, Selig S, Keshet I, Cedar H: Replication structure of the human beta-globin gene domain. Nature 1993, 366(6455):588-590.

56. van der Meijden CM, Lapointe DS, Luong MX, Peric-Hupkes D, Cho B, Stein JL, van Wijnen AJ, Stein GS: Gene profiling of cell cycle progression through $S$-phase reveals sequential expression of genes required for DNA replication and nucleosome assembly. Cancer Res 2002, 62(I I ):3233-3243.

57. White AE, Livanos EM, Tlsty TD: Differential disruption of genomic integrity and cell cycle regulation in normal human fibroblasts by the HPV oncoproteins. Genes Dev 1994, 8(6):666-677.

58. TSRI Cytometry index [http://facs.scripps.edu/facsindex.html]

59. Kelley JM, Field CE, Craven MB, Bocskai D, Kim UJ, Rounsley SD, Adams MD: High throughput direct end sequencing of BAC clones. Nucleic Acids Res 1999, 27(6): I 539-I546.

60. Good P: Permutation Tests: A Practical Guide to Resampling Methods for Testing Hypotheses. New York, Springer-Verlag; 1994.

61. Heffernan TP, Simpson DA, Frank AR, Heinloth AN, Paules RS, Cordeiro-Stone M, Kaufmann WK: An ATR- and Chkl-dependent S checkpoint inhibits replicon initiation following UVCinduced DNA damage. Mol Cell Biol 2002, 22(24):8552-856 I.

62. Doggett NA, Cordeiro-Stone M, Chae CB, Kaufman DG: Timing of proto-oncogene replication: a possible determinant of early S phase sensitivity of $\mathrm{C} 3 \mathrm{H}$ I0TI/2 cells to transformation by chemical carcinogens. Mol Carcinog I988, I(I):4 I-49.

63. Primer3 Input (primer3_www.cgi v 0.2) [http:// frodo.wi.mit.edu/cgi-bin/primer3/primer3 www.cgi]
Publish with Biomed Central and every scientist can read your work free of charge

"BioMed Central will be the most significant development for disseminating the results of biomedical research in our lifetime. "

Sir Paul Nurse, Cancer Research UK

Your research papers will be:

- available free of charge to the entire biomedical community

- peer reviewed and published immediately upon acceptance

- cited in PubMed and archived on PubMed Central

- yours - you keep the copyright
BiolMedcentral 